\title{
From houses divided to partnering across disciplines: disambiguating human ARTs in 2021
}

\author{
David F. Albertini ${ }^{1}$
}

Published online: 2 December 2021

(c) The Author(s), under exclusive licence to Springer Science+Business Media, LLC, part of Springer Nature 2021

Looking back over the events of the past year for JARG exposes much more about the branding of reproductive medicine than could not have been imagined one year ago. Of course, serving our readership with a broad base of clinical and fundamental reproductive biology remained a main staple, and from this column alone, every effort has been made to supplement the original research contained within these pages with an admixture of opinion and discourse germane to the practice of human ARTs. Crossing the chasm between the basic and clinical scientific underpinnings, while a driving force traditionally for the utopian "bench to bedside" imperative, has been anything but enabled as the search for truth in our discipline has strayed well beyond the norms and expectations demonstrated by other medical specialties.

The ironic twist is that the biomedical research enterprise historically failed to recognize reproductive medicine (and biology for that matter) with the levels of funding routinely afforded those agencies and governments rightly aimed at curing life-threatening and debilitating diseases lying outside the realm of reproductive health. With recognition from the WHO years ago, and a general shift to preventive and personalized medicine philosophies, we now find ourselves as a discipline firmly entrenched in the quality of life realm of healthcare.

Our final issue for 2021 uncovers and shares with our readership a range of papers sure to draw attention to the division of sentiments exacerbated by the subset of topics continuing to fuel discord and confusion among physicians, scientists, embryologists, and patients. From tinkering with media compositions that might minimize negative metabolic consequences for the embryo, to automation of laboratory practices, to deciphering morphokinetic data sets with respect to lifestyle variations, our coverage continues to reveal just how far we are from truly understanding the

David F. Albertini

eicjarg@gmail.com

1 Bedford Research Foundation, Bedford, MA, USA basis for so much we do. The rich landscape of "mixed messages" in human ARTs over add-ons parallels the confused and de-focused state of affairs we have witnessed over the COVID-19 pandemic.

Disambiguating reproductive medicine and its offerings will not be a straightforward endeavor. Research in reproductive medicine is now in the hands of industry. Attested to by the kinds of studies eager to gain the public's attention, as Sanders and colleagues report in this issue (Sanders KD, Silvestri G, Gordon T, Griffin DK. Analysis of IVF live birth outcomes with and without preimplantation genetic testing for aneuploidy (PGT-A): UK Human Fertilisation and Embryology Authority data collection 2016-2018. J Assist Reprod Genet. 2021 https://doi.org/10.1007/s10815021-02349), comes the troubling situation and associated risks when data is analyzed without taking into consideration details that can be misleading to the reader. Scriven puts this work under the microscope for our followers and, in so doing, brings to light many of the nuances contained within (Insights into the utility of preimplantation genetic testing from data collected by the HFEA, https://doi.org/10.1007/ s10815-021-02369).

All matters mosaic continue to dominate this conversation in search of something more in the way of a compelling data set that would cut to the core of some fundamental sciencesome truth please! So here in the $11^{\text {th }}$ hour of a year in which mixed messages have been the norm, not the exception, comes an important study from the group of Z.-J. Chen asking to what extent does performing PGT-A make a difference in live birth outcome [1]. The details stand for themselves and will add to what is becoming clear that PGT-A is not for all patients and could be overkill for some. Nevertheless, the ambiguities facing physicians and patients continue to propagate a sense of mistrust in our field that extends well beyond PGT-A and deep into the inner workings of the peer review process. With so little research being funded outside the business sector, this kind of situation should have been anticipated and with it a way to deal the distinctions between 
conflicts of interest soiling the interface between investigative integrity and revenue streams. Against this backdrop, we encourage our readership to engage the "Sounding Board" editorial from the likes of Mastenbroek, de Wert, and Adashi examining trends in reproductive medicine with respect to the introduction of new methodologies [2]. More than anything else, articles like this serve to draw our attention to the many reasons why opinions formulated on the presumed basis of rigorous testing and unbiased evaluation of data sets are divergent to an extreme and create the divisive attitude among the many constituencies in our profession that has escalated over the past year.

What we hoped would have been a year of recovery and progress in reproductive medicine instead continues to resemble more a minefield of rhetoric as the ways of commercialism in human ARTs move the spirit of discovery further and further into the background. Here is to a new course for progress in human ARTs and Genetics in the coming year. Thank you for your continued support of JARG and to the tireless efforts of the members of our Editorial Board.

\section{References}

1. Yan J, Qin Y, Zhao H, Sun Y, Gong F, Li R, et al. Live Birth with or without preimplantation genetic testing for aneuploidy. $\mathrm{N}$ Engl J Med. 2021;385(22):2047-58.

2. Mastenbroek S, de Wert G, Adashi EY. The imperative of responsible innovation in reproductive medicine. $\mathrm{N}$ Engl J Med. 2021;385(22):2096-100.

Publisher's note Springer Nature remains neutral with regard to jurisdictional claims in published maps and institutional affiliations. 